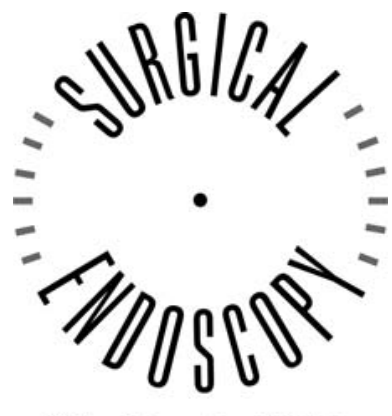

and Other Interventional Techniques

\title{
Robot-assisted laparoscopic surgery of the infrarenal aorta
}

\section{The early learning curve}

\author{
J. Diks, ${ }^{1}$ D. Nio, ${ }^{2}$ V. Jongkind, ${ }^{1}$ M. A. Cuesta, ${ }^{1}$ J. A. Rauwerda, ${ }^{1}$ W. Wisselink ${ }^{1}$ \\ ${ }^{1}$ Department of Surgery, Vrije Universiteit University Medical Center, PO Box 7057, 1007 MB, Amsterdam, The Netherlands \\ ${ }^{2}$ Department of Surgery, Spaarne Ziekenhuis, PO Box 770, 2130 AD, Hoofddorp, The Netherlands
}

Received: 15 October 2006/Accepted: 16 October 2006/Online publication: 1 March 2007

\begin{abstract}
Background: Recently introduced robot-assisted laparoscopic surgery (RALS) facilitates endoscopic surgical manipulation and thereby reduces the learning curve for (advanced) laparoscopic surgery. We present our learning curve with RALS for aortobifemoral bypass grafting as a treatment for aortoiliac occlusive disease. Methods: Between February 2002 and May 2005, 17 patients were treated in our institution with robot-assisted laparoscopic aorto-bifemoral bypasses. Dissection was performed laparoscopically and the robot was used to make the aortic anastomosis. Operative time, clamping time, and anastomosis time, as well as blood loss and hospital stay, were used as parameters to evaluate the results and to compare the first eight (group 1) and the last nine patients (group2).

Results: Total median operative, clamping, and anastomosis times were $365 \mathrm{~min}$ (range: 225-589 $\mathrm{min}$ ), 86 min (range: 25-205 $\mathrm{min}$ ), and $41 \mathrm{~min}$ (range: 22-110 min), respectively. Total median blood loss was $1,000 \mathrm{ml}$ (range: $100-5,800 \mathrm{ml}$ ). Median hospital stay was 4 days (range: $3-57$ days). In this series 16/18 anastomoses were completed with the use of the robotic system. Three patients were converted (two in group 1, one in group 2), and one patient died postoperatively (group 1). Median clamping and anastomosis times were significantly different between groups 1 and 2 (111 min [range: 85-205 min] versus $57.5 \mathrm{~min}$ [range: $25-130 \mathrm{~min}$ ], $p<0.01$ and $74 \mathrm{~min}$ [range: $40-110 \mathrm{~min}$ ] versus $36 \mathrm{~min}$ [range: $22-69$ $\min ], \quad p<0.01$, respectively) Total operative time, blood loss, and hospital stay showed no significant difference between groups 1 and 2 .

Conclusions: Robot-assisted aortic anastomosis was shown to have a steep learning curve with considerable reduction of clamping and anastomosis times. However, due to a longer learning curve for laparoscopic dissection
\end{abstract}

Presented at SAGES 2006, April 26-29 2006, Dallas, Texas, USA Correspondence to: W. Wisselink of the abdominal aorta, operation times were not significantly shortened. Even with robotic assistance, laparoscopic aortoiliac surgery remains a complex procedure.

Key words: Robot - Laparoscopy - Aorta Learning curve

Over the last decade, laparoscopic techniques in vascular surgery have evolved from laparoscopy-assisted and hand-assisted to total laparoscopic procedures. A small group of pioneers have shown it to be a feasible technique for both the treatment of aortoiliac occlusive disease as for aneurysm repair $[1,3,5,8,11]$. However, vascular surgeons seem reluctant to introduce it into their everyday practice. Their reluctance can be explained by the technical difficulties of this approach. Laparoscopic dissection of the abdominal aorta is a difficult procedure; due to collapse of the operating field or migrating bowels it can be difficult to maintain a clear view. Also, creation of the aortic anastomosis is challenging, demanding a great deal of practice and technical skill. The factors may contribute to a long learning curve in laparoscopic vascular procedures.

Recently introduced robotic surgical systems are known to facilitate technically challenging laparoscopic techniques, such as suturing, knot-tying, and creation of intracorporeal anastomoses [16]. Introducing these robotic systems to aid in laparoscopic vascular procedures may help overcome long learning curves and the necessity to maintain ones laparoscopic skills on a more than regular basis.

\section{Methods}

After an initial series of eight robot-assisted laparoscopic aortobifemoral bypasses for aortoiliac occlusive disease [13], we expanded our series to a total of 17 patients between April 2004 and May 2005. The 
latter nine patients were all operated with use of a da Vinci surgical system (Intuitive Surgical inc., Sunnyvale, CA, USA). During this period (April 2004-May 2005), we operated on a total of 21 consecutive patients for aortoiliac occlusive disease: 9 robot-assisted laparoscopic aortobifemoral bypasses, 3 endarterectomies (limited disease), and 9 conventional aortobifemoral bypasses via a transperitoneal route. Reasons for conventional operations were replacement of infected prostheses $(n=4)$, abdominal adhesions in patients with previous abdominal surgery $(n=2)$, redo-surgery of an occluded prosthesis $(n=1)$, and extensive renal and visceral occlusive disease necessitating suprarenal clamping $(n=1)$. In these cases $(n=8)$, robot-assisted laparoscopic surgery (RALS) was not deemed suitable because of our limited experience. One patient needed emergency surgery for acute ischemia when the robot was not available.

All procedures were conducted by the same team of surgeons (an experienced vascular surgeon (W.W.) and an experienced laparoscopic surgeon (M.A.C.)), while the same team of (scrub-) nurses attended all the operations. Surgical assistants rotated, and an engineer from Intuitive Surgical was present to assist at all operations.

Sixteen men and 1 woman, median age 55 years (range: 36-72 years) were operated for aortoiliac occlusive disease with disabling intermittent claudication. Preoperative imaging consisted of arteriogram $(n=16)$ or magnetic resonance arteriogram (MRA) $(n=1)$. All patients had undergone previous attempts at revascularization with either percutaneous transluminal angioplasty (PTA) $(n=4)$, stent placement $(n=6)$, or both $(n=7)$. Median body mass index (BMI) was 25.4 (range: 19.8-36.8), and median ankle-arm index (AAI) was 0.70 (range $0.90-0.35$ ) at rest and 0.35 (range $0.13-0.52$ ) after exercise. All data were obtained prospectively.

\section{Surgical technique}

Details of different surgical techniques have been described elsewhere $[1,3,5,8,10,11,18]$. After performance of the initial transabdominal approach with the "apron" technique [10] and a retroperitoneal approach [18], we preferred the transabdominal approach with extreme patient-rotation as described by Coggia et al. [5]. Briefly, under general anesthesia, the patient is positioned supine with a Pelvic Tilt pillow (O.R. Comfort, LLC, Branchburg, NJ, USA) positioned under the left flank. Via small groin incisions, the common femoral arteries are exposed on both sides.

The operating table is then maximally rotated and the pillow is inflated until a right lateral and rotated decubitus position is achieved, with the patient's abdomen rotated at 85-90 degrees.

The surgeon stands at the right side of the patient, facing the patient's abdomen and the video monitor, which is located at the patients left side. Six 12-mm trocars are inserted, as shown in Figure 1.

Laparoscopic transabdominal dissection of the infrarenal aorta and bifurcation are performed with a 30-degree endoscope (Storz Endoskop Produktions GmbH, Tuttlingen, Germany). After dissection of the left colon, a fan retractor is placed into an Endoscope Holding system (Karl Storz GmbH \& Co. KG, Tuttlingen, Germany) to keep the bowel from migrating into the operative field. The lumbar arteries are clipped with a Ligasure $^{\mathrm{TM}}$ Vessel Sealing System (Valleylab, Boulder, CO, USA), and the inferior mesenteric artery is temporarily occluded.

Two retroperitoneal tunnels are prepared from the groin incision toward the aorta by passing a blunt clamp and visualizing its intraabdominal passage with the endoscope.

Aortic clamps are placed in position; the proximal clamp is inserted through an incision in the abdominal wall, the distal clamp is inserted through an earlier placed 12-mm trocar (Fig. 1). Then the robotic system, which was previously covered with a sterile drape, is introduced into the surgical field. The surgeon moves behind a remote console, from which the robotic arms are controlled. The endoscope is replaced by a 30-degree 3D-endoscope of the surgical system.

After systemic heparinization, the aorta is clamped just distal to the renal arteries and below the inferior mesenteric artery. An aortotomy is made with a pair of pots scissors (Endowrist ${ }^{\mathrm{TM}}$ Pots Scissors, Intuitive Surgical, Sunnyvale, CA, USA). A bifurcated polytetrafluororethylene (PTFE; W.L. Gore and Associates, Flagstaff, AZ, USA) prosthesis is stained orange with rifampicine to prevent light reflection, and an end-to-side anastomosis is made with a CV-4 PTFE (W. L. Gore and Associates, Flagstaff, AZ, USA) running suture with two robotic needle drivers (Endowrist ${ }^{\circledR}$ Needle Drivers).

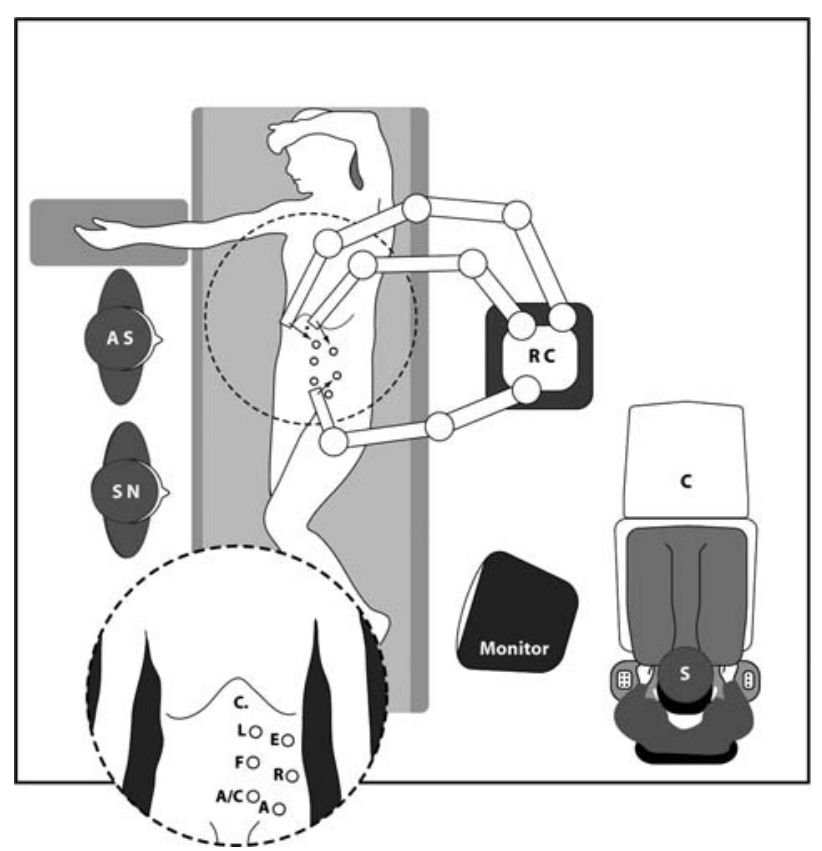

Fig. 1. Setup in the operating room and trocar positions: RC: robotic cart; C: robot-console; S: surgeon; AS: assistant; SN: scrub nurse. Inset: C: aortic clamps; F: fan retractor; E: surgical endoscope; R: right robotic arm; L: left robotic arm; A: assistants' ports.

Following completion of the aortic anastomosis, the two graft limbs are tunnelled to the groins, where a conventional end-to-side anastomosis is performed to the common femoral artery.

\section{Statistical analysis}

Statistical analysis was performed using a Mann Whitney $U$-test in SPSS 12.0 for Windows ${ }^{\mathrm{TM}}$ to compare operative parameters between our earlier 8 patients (group 1) and our more recent 9 patients (group $2)$. A $p$ value $<0.05$ was considered statistically significant.

\section{Results}

In all patients, an aortobifemoral bypass graft was successfully inserted. However, conversion to open surgery was necessary in three patients, two of whom (patients 6 and 8) have been described previously [13]. A third conversion (patient 9) was required by a technical problem with the robotic system; the battery was not recharged and it was considered unsafe to proceed without a back-up energy source. One patient (no. 11) had to undergo reoperation on postoperative day one, to correct leakage from the prosthesis. A laparotomy was performed and a hematoma was encountered in the retroperitoneal space. The prosthesis showed a small puncture hole, probably from robotic manipulation. One patient (no. 3) died unexpectedly on postoperative day 3 due to a massive myocardial infarction [13].

Total median operative time was 365 min (range: 225-589 $\mathrm{min}$ ), with a median clamping time of $86 \mathrm{~min}$ (range: 25-205 $\mathrm{min}$ ) and a median anastomosis time of 41 min (range: $22-110 \mathrm{~min}$ ). Median blood loss was 1,000 $\mathrm{ml}$ (range: 100-5,800 ml). Median hospital stay was 4 days (range: $3-57$ days), and we have a median follow-up of 18 months (range: 6-48 months). 
Table 1. Median parameters (range) and statistical significance

\begin{tabular}{llllll}
\hline & Operative time $(\mathrm{min})$ & Clamp time $(\mathrm{min})$ & Anastomosis time $(\mathrm{min})$ & Blood loss (ml) & Hospital stay (days) \\
\hline First 8 & $405(260-589)$ & $111(85-205)$ & $74(40-110)$ & $900(200-5,800)$ & $7.5(3-57)$ \\
Latter 9 & $339(225-465)$ & $57.5(25-130)$ & $36(22-69)$ & $950(100-1,800)$ & $4(4-15)$ \\
$p$ Value & NS & $<0.01$ & $<0.01$ & NS & NS \\
\hline
\end{tabular}

Table 2. Parameters per patient

\begin{tabular}{|c|c|c|c|c|c|c|c|c|}
\hline & $\begin{array}{l}\text { OR time } \\
(\mathrm{min})\end{array}$ & $\begin{array}{l}\text { Blood loss } \\
(\mathrm{ml})\end{array}$ & $\begin{array}{l}\text { Clamp-time } \\
\text { (min) }\end{array}$ & $\begin{array}{l}\text { Anastomosis } \\
\text { time (min) }\end{array}$ & $\begin{array}{l}\text { ICU } \\
\text { stay (days) }\end{array}$ & $\begin{array}{l}\text { Hospital } \\
\text { stay (days) }\end{array}$ & Conversion & $\begin{array}{l}\text { Follow-up } \\
\text { (months) }\end{array}$ \\
\hline 1 & 290 & 200 & 104 & 74 & 1 & 4 & No & 48 \\
\hline 2 & 260 & 200 & 90 & 60 & 1 & 6 & No & 48 \\
\hline 3 & 380 & 700 & 125 & 65 & 1 & 8 & No & 36 \\
\hline 4 & 420 & 1,000 & 175 & 85 & 1 & 4 & No & 36 \\
\hline 5 & 455 & 800 & 205 & 110 & 3 & 3 & No & 36 \\
\hline 6 & 589 & 5,800 & 105 & 40 & 16 & 57 & Yes & 24 \\
\hline 7 & 390 & 1,650 & 117 & 60 & 1 & 6 & No & 24 \\
\hline 8 & 495 & 3,000 & 85 & $\mathrm{X}$ & 1 & 10 & Yes & 24 \\
\hline 9 & 335 & 1,000 & 25 & $X$ & 1 & 11 & Yes & 18 \\
\hline 10 & 260 & 1,150 & 70 & 30 & 1 & 4 & No & 12 \\
\hline 11 & 465 & 900 & 130 & 40 & 3 & 15 & No & 12 \\
\hline 12 & 355 & 1,100 & 55 & 25 & 1 & 4 & No & 12 \\
\hline 13 & 388 & 600 & 60 & 69 & 1 & 4 & No & 12 \\
\hline 14 & 343 & 1,350 & 55 & 39 & 1 & 4 & No & 12 \\
\hline 15 & 310 & 600 & 60 & 36 & 1 & 4 & No & 6 \\
\hline 16 & 225 & 100 & 35 & 22 & 1 & 4 & No & 6 \\
\hline 17 & 365 & 1,800 & 86 & 41 & 1 & 4 & No & 6 \\
\hline
\end{tabular}

OR: operating room; ICU: intensive care unit

When group 1 is compared to group 2, a significant difference is seen in clamp time (median $111 \mathrm{~min}$ [range: 85-205 min] versus median 57.5 min [range: 25-130 $\min ], p<0.01$ ) and in anastomosis time (median 74 min [range: $40-110 \mathrm{~min}$ ] versus median $36 \mathrm{~min}$ [range: $22-69 \mathrm{~min}], p<0.01)$. No significant difference was seen in median operative time (405 min [range: $260-589$ min] versus 339 min [range: $225-465 \mathrm{~min}$ ]), median blood loss (900 ml [range: $200-5,800 \mathrm{ml}$ ] versus $950 \mathrm{ml}$ [range: $100-1,800 \mathrm{ml}$ ]), and hospital stay (7.5 days [range 3-57] versus 4 days [range: 4-15]) (Table 1).

During follow-up, all patients had a duplex examination at 6 months to verify patency of the prosthesis. No stenoses or false aneurysms were encountered. The AAI was normal $(>1.0)$ in all but one patient $(0.7$ in the rest, as a result of pre-existing femoral occlusive disease). All patients remained free of intermittent claudication.

\section{Discussion}

Since the introduction of minimally invasive vascular surgery, techniques such as laparoscopy-assisted and hand-assisted laparoscopic procedures for aortobifemoral bypass grafting have been developed $[2,17]$ In such procedures the aortic dissection is performed laparoscopically in contrast to the conventional "open" method, which requires a long abdominal incision. Laparoscopic creation of an aortic anastomosis however, is indisputably challenging and requires a great deal of practice and experience before it can be applied in everyday clinical practice $[7,12]$.
The addition of robotic assistance to these procedures offers an ergonomic and natural interface between the surgeon's hands and the instrument tips, as well as increased freedom of motion provided by the wrist action of the robotic instruments. It therefore seems to facilitate creation of the aortic anastomosis, making a total laparoscopic procedure for aortobifemoral bypass grafting easier and more accessible to the "common" vascular surgeon.

Laparoscopic dissection of the abdominal aorta can be performed via a retroperitoneal route and a transabdominal route. The retroperitoneal route [18] is an easy and fast technique, The obtained space however, is small and tends to collapse when suction is used. In case of bleeding, conversion to open surgery is nearly unavoidable.

The "apron" technique [10] is a time-consuming technique and the thin apron flap tears easily, which often results in conversion. After initial experience with both these techniques, we opted for the transabdominal route [5], using extreme patient rotation. This technique offers a clear and stable operative field, using a fan retractor to keep bowels from migrating into the operative field.

With the addition of robotic technology to conventional laparoscopic surgery, we have shown a considerable shortening of the learning curve with regard to creation of the aortic anastomosis. Compared to various larger series $[4,7,9,12,14,15]$, the aortic anastomosis time and the aortic clamp time in this series became acceptable after the first 8 patients. In our institution patients are treated by endovascular techniques for 
aortoiliac occlusive disease, and only a few patients need surgery. Even without a daily or weekly routine, we still showed improvement in our anastomosis times. This suggests that robotic manipulation does not require as much practice and maintenance of skills as does conventional laparoscopy.

However, the greater part of this procedure consists of the laparoscopic dissection of the abdominal aorta. From our search into the "best" approach, and because of the technical challenge of this advanced laparoscopic procedure (e.g., control of bleeding [6]), we have yet to complete our learning curve for the laparoscopic part of this procedure before a considerable drop in operative time can be anticipated.

RALS is an expensive method, due to the robotic system, its instruments, and maintenance of the system. Although a cost analysis was not conducted in our study, it can be assumed to be more expensive then conventional technologies and this should be considered before applying RALS in any institution. With new technological developments on the horizon, robotic systems may rapidly become less expensive, less bulky, and more manageable in the near future, making their use accessible for a greater audience.

In conclusion, after 8 cases we survived the learning curve for the robotic part of RALS for aortobifemoral bypass grafting. The most critical part of the operation, the aortic clamp time, has been more than halved. But even with robotic facilitation of the aortic anastomosis, long operative times are still anticipated due to the learning curve associated with laparoscopic aortic dissection.

\section{References}

1. Ahn SS, Hiyama DT, Rudkin GH, Fuchs GJ, Ro KM, Concepcion B (1997) Laparoscopic aortobifemoral bypass. J Vasc Surg 26: $128-132$

2. Alimi YS, De Caridi G, Hartung O, Barthelemy P, Aissi K, Otero A, Amer M, Giorgi R (2004) Laparoscopy-assisted reconstruction to treat severe aortoiliac occlusive disease: early and midterm results. J Vasc Surg 39: 777-783

3. Alimi YS, Hartung O, Orsoni P, Juhan C (2000) Abdominal aortic laparoscopic surgery: retroperitoneal or transperitoneal approach? Eur J Vasc Endovasc Surg 19: 21-26
4. Barbera L, Mumme A, Metin S, Zumtobel V, Kemen M (1998) Operative results and outcome of twenty-four totally laparoscopic vascular procedures for aortoiliac occlusive disease. J Vasc Surg 28: $136-142$

5. Coggia M, Bourriez A, Javerliat I, Goeau-Brissonniere O (2002) Totally laparoscopic aortobifemoral bypass: a new and simplified approach. Eur J Vasc Endovasc Surg 24: 274-275

6. Coggia M, Javerliat I, Di Centa I, Alfonsi P, Colacchio G, Kitzis M, Goeau-Brissonniere O (2005) Total laparoscopic versus conventional abdominal aortic aneurysm repair: a case-control study. J Vasc Surg 42: 906-910

7. Coggia M, Javerliat I, Di Centa I, Colacchio G, Leschi JP, Kitzis M, Goeau-Brissonniere OA (2004) Total laparoscopic bypass for aortoiliac occlusive lesions: 93-case experience. J Vasc Surg 40: 899-906

8. Dion YM, Gracia C (2001) Totally laparoscopic aortic abdominal aortic aneurysm repair. J Vasc Surg 33: 181-185

9. Dion YM, Griselli F, Douville Y, Langis P (2004) Early and midterm results of totally laparoscopic surgery for aortoiliac disease: lessons learned. Surg Laparosc Endosc Percutan Tech 14: 328 334

10. Dion YM, Thaveau F, Fearn SJ (2003) Current modifications to totally laparoscopic "apron technique." J Vasc Surg 38: 403-406

11. Kolvenbach R, Ceshire N, Pinter L, Da Silva L, Deling O, Kasper AS (2001) Laparoscopy-assisted aneurysm resection as a minimal invasive alternative in patients unsuitable for endovascular surgery. J Vasc Surg 34: 216-221

12. Lin JC, Kolvenbach R, Schwierz E, Wassiljew S (2005) Total laparoscopic aortofemoral bypass as a routine procedure for the treatment of aortoiliac occlusive disease. Vascular 13: 80-83

13. Nio D, Diks J, Linsen MA, Cuesta MA, Gracia C, Rauwerda JA, Wisselink W (2005) Robot-assisted laparoscopic aortobifemoral bypass for aortoiliac occlusive disease: early clinical experience. Eur J Vasc Endovasc Surg 29: 586-590

14. Olinde AJ, McNeil JW, Sam A, Hebert SA, Frusha JD (2005) Totally laparoscopic aortobifemoral bypass: a review of 22 cases. J Vasc Surg 42: 27-34

15. Remy P, Deprez AF, D'hont Ch, Lavigne JP, Massin H (2005) Total laparoscopic aortobifemoral bypass. Eur J Vasc Endovasc Surg 29: 22-72

16. Ruurda JP, Wisselink W, Cuesta MA, Verhagen en Broeders HJ IAMJ (2004) Robot-assisted versus standard videoscopic aortic replacement. A comparative study in pigs. Eur J Vasc Endovasc Surg 27: 501-506

17. Silva L, Kolvenbach R, Pinter L (2002) The feasibility of handassisted laparoscopic aortic bypass using a low transverse incision. Surg Endosc 16: 173-176

18. Wisselink W, Cuesta MA, Berends FJ, van den Berg FG, Rauwerda JA (2000) Retroperitoneal endoscopic ligation of lumbar and inferior mesenteric arteries as a treatment of persistent endoleak after endoluminal aortic aneurysm repair. J Vasc Surg 31: $1240-1244$ 